\title{
AMPLIAÇÃO DA JORNADA ESCOLAR E SEUS ASPECTOS NORMATIVOS: MAS, QUE (CON)FORMAÇÃO?
}

\author{
Saraa César Mól - saraa_mol@ymail.com \\ Simone Pereira Santos Simone - simonep.simone@yahoo.com.br \\ Felipe Rodrigues de Oliveira Campos - camposfelipe37@ gmail.com
}

Resumo: A ampliação da jornada escolar significa uma educação em tempo integral? Que dimensões formativas esse processo envolve? Contempla uma educação integral? Procurando esclarecer a comumente confusão conceitual que abarca essas questões, este trabalho tem como objetivo identificar as diferenças entre ampliação da jornada escolar, educação em tempo integral e educação integral, situando-os no ordenamento jurídico educacional brasileiro, no que tange ao Ensino Fundamental. Especificamente pretendemos caracterizar tais conceitos; bem como identificar os aportes normativos legais que os sustentam no contexto brasileiro. Foi realizada uma pesquisa bibliográfica a partir de autores como Coelho (2016), Cavaliere (2007), Libâneo (2015) e Moll (2012). A pesquisa documental também subsidiou as análises sobre os referidos conceitos, considerando os ordenamentos normativos educacionais brasileiros. Finalizamos compreendendo que, na contramão da melhoria da qualidade da educação, a ampliação da jornada escolar, bem como a educação integral e(m) tempo integral parecem con(formar) os sujeitos à sua condição de pobreza.

Palavras-chave: Ampliação da jornada escolar; educação integral e (m) tempo integral; aportes normativo-legais.

\section{INTRODUÇÃO}

A ampliação da jornada escolar significa uma educação em tempo integral? Que dimensões formativas esse processo envolve? E contempla uma educação integral? Esse debate tem integrado as recentes políticas públicas educacionais que, amparadas por ordenamentos legais, têm previsto a ampliação da jornada escolar, a educação em tempo integral e/ou a educação integral.

É procurando esclarecer a comumente confusão conceitual que abarca esses conceitos que este trabalho tem como objetivo identificar as diferenças entre ampliação da jornada escolar, educação em tempo integral e educação integral. Especificamente pretendemos (1) caracterizar tais conceitos; (2) bem como situá-los frente aos aportes jurídico educacionais no contexto brasileiro, no que tange ao Ensino Fundamental.

Para tanto, foi realizada uma pesquisa bibliográfica, a fim de entender o que a literatura mostra sobre essa temática. Essa pesquisa se deu a partir de autores que contribuíram para as reflexões acerca dos referidos conceitos. É o caso de Coelho (2016), Cavaliere (2007), Libâneo 
(2015) e Moll (2012). A pesquisa documental também subsidiou as análises sobre os referidos conceitos, é o caso da Lei 9.394 de1996 (BRASIL, 1996) - Lei de Diretrizes e Bases da Educação Nacional (LDBEN), da Lei n. 13.005, de 2014 (BRASIL, 2014) referente ao Plano Nacional de Educação (PNE) (2014-2024), entre outras.

O presente trabalho apresenta mais um tópico, além da introdução, no qual apresentamos a pesquisa bibliográfica, a pesquisa documental e a análise dos dados. Finalizamos com as considerações finais, trazendo alguns apontamentos a partir do estudo realizado.

\section{EM TEMPO, UMA DISCUSSÃO: AMPLIAÇÃO DA JORNADA ESCOLAR, EDUCAÇÃO EM TEMPO INTEGRAL E EDUCAÇÃO INTEGRAL}

A temática da ampliação da jornada escolar no Brasil não é assunto novo, mas é nos últimos anos que vem ganhando amplitude normativa e sendo alvo de investimento por parte de políticas públicas governamentais. Nesse contexto, muitos são os sentidos atribuídos à ampliação da jornada escolar, à educação em tempo integral e à educação integral.

Segundo Cavaliere (2002) a organização social do tempo é um elemento que simultaneamente reflete e constitui as formas organizacionais mais abrangentes na sociedade. Dentre os meios de organização do tempo social destaca-se o tempo de escola que, sendo a mais importante referência para a vida das crianças e adolescentes, tem sido, no mundo contemporâneo, um pilar para a organização da vida em família e da sociedade em geral. O tempo é um elemento fundamental para a compreensão, não apenas dos processos civilizatórios num sentido mais amplo, mas também dos processos de criação, acumulação e distribuição de riquezas materiais e simbólicas nas sociedades.

Para a autora, cresce no Brasil o número de projetos na Educação Básica pública que tem como característica a ampliação da jornada escolar. Com a abertura política, na década de 1980, ocorreram algumas experiências nessa direção, sendo a de mais longa duração e repercussão, no que tange aos anos 1980 e 1990, a dos Centros Integrados de Educação Pública (CIEPs), no Rio de Janeiro.

No que diz respeito à legislação, segundo o Art. 34 da LDBEN - Lei n. 9. 394, de 1996 (BRASIL, 1996), a jornada escolar no Ensino Fundamental incluirá pelo menos quatro horas de 
trabalho efetivo em sala de aula, sendo progressivamente ampliado o período de permanência na escola. Esse artigo aponta a jornada escolar como o período em que a criança e o adolescente estão sob a responsabilidade da escola, denota sobre um tempo mínimo da jornada escolar de 4 horas diárias com vista ao seu aumento.

Mas, a que fins a ampliação da jornada escolar pode estar ligada? Para Cavaliere (2009), a ampliação da jornada escolar nas escolas pode ser entendida e justificada de diversas formas: (a) como forma de se alcançar melhores resultados da ação escolar sobre os indivíduos, devido à maior exposição dessas práticas e rotinas escolares; (b) como adequação da escola às novas condições da vida urbana, das famílias e particularmente da mulher; (c) como parte integrante da mudança na própria concepção de educação escolar, isto é, no papel da escola na vida e na formação dos indivíduos. Segundo a referida autora, a última alternativa citada acima é a que mais desafia a reflexão educacional abrangente e, de certa forma, engloba as anteriores. Percebemos, assim, que a ampliação da jornada escolar, no Brasil, se apresenta como uma forma de promover melhores resultados escolares e também como forma de adaptação à vida urbana, mas a ampliação da jornada escolar não deveria considerar o desenvolvimento do ser humano em sua plenitude?

Cavaliere (2009) apresenta dois modelos de ampliação da jornada escolar: escolas de tempo integral e alunos em tempo integral. A primeira dessas tendências, escolas de tempo integral, é histórica e se funda na centralidade da instituição escolar, onde existe uma construção de uma proposta pedagógica para escolas de tempo integral que repensa as funções da instituição escolar na sociedade brasileira, que a fortaleça através de melhores equipamentos, do enriquecimento de suas atividades e das condições adequadas de estudo e trabalho para alunos e professores. Isso poderá trazer algo de novo e que represente crescimento na qualidade do trabalho educativo, trabalhando para que os alunos tenham conhecimentos historicamente acumulados pela humanidade. A ampliação da jornada escolar, nesse sentido, é acompanhada dos conhecimentos científicos, estéticos, éticos, expressivo comunicacionais e físicos, integrados ao trabalho pedagógico, apresentando ao aluno algumas dessas possibilidades de formação, para que possam fazer suas escolhas.

Já o modelo alunos em tempo integral, valoriza a permanência dos alunos, caracterizando um projeto socioeducativo. Nesta visão contemporânea são acrescentadas atividades 
socioeducativas que são realizadas fora das escolas, numa perspectiva de que a escola não é o único espaço de aprendizagem e que outras instituições devem estar articuladas, a exemplo das organizações não- governamentais (CAVALIERE, 2009).

Como essa organização é prevista nos aportes normativos? A LDBEN aponta no Art. 34, $\S 2^{\circ}$ que o Ensino Fundamental será ministrado progressivamente em tempo integral, a critério dos sistemas de ensino. Já no $\S 5^{\circ}$ do art. 87 , indica a conjugação de todos os esforços com vistas à progressão das redes escolares públicas urbanas de Ensino Fundamental para o regime de escolas de tempo integral

Do ponto de vista conceitual, encontramos a primeira definição para a educação em tempo integral no Plano Nacional de Educação (PNE-2001/2010) - Lei n. 10.172, de 2001 (BRASIL, 2001). O plano, em sua meta 21 , dispõe sobre o aumento progressivo da jornada escolar, visando expandir a escola de tempo integral, cujo período de atendimento é especificado em 7 horas diárias, com o quantitativo suficiente de professores e funcionários (BRASIL, 2001).

Neste cenário, o PNE atrela o tempo integral à melhoria nos resultados, como estratégia para melhorar a aprendizagem na direção do alcance das exigências internacionais para a Educação Básica no sentido de reduzir os índices de analfabetismo, repetência e evasão, indicando uma concepção eficienticista de educação. Além disso, o referido PNE - (BRASIL, 2001) - estabeleceu a prioridade de tempo integral para as crianças de camadas sociais mais necessitadas, para as crianças de idades menores e para as famílias de renda mais baixa, quando os pais trabalham fora de casa. Ou seja, percebemos que até agora que a educação em tempo integral tem sido indicada como um reforço para os mais pobres.

Ainda sobre a legislação, temos um importante marco, no que diz respeito ao financiamento da educação em tempo integral no Brasil em 2007. Trata-se do Fundo de Manutenção e Desenvolvimento da Educação Básica e de Valorização dos Profissionais da Educação (FUNDEB), de natureza contábil. Trata-se de um mecanismo de redistribuição de recursos destinados à Educação Básica que tem como objetivo fazer com que haja menos desigualdade de recursos entre as redes de ensino e dá segurança financeira aos municípios e estados para expandirem seu número de matrículas, os orientado no cumprimento de suas responsabilidades com a Educação (BRASIL, 2007b). 
Dessa forma, o fundo associa o tempo integral a todas as etapas da Educação Básica. Nesse sentido, o Decreto n. 6.253,13 de novembro de 2007 (BRASIL, 2007b), considera a Educação Básica em tempo integral a jornada escolar com duração igual ou superior a sete horas diárias, durante todo o processo letivo, compreendendo o tempo total que um mesmo aluno permanece na escola ou em atividades escolares. É válido ressaltar que foi a primeira vez que a legislação especificou que o tempo integral pode ocorrer em atividades fora das escolas, indicando uma abertura do protagonismo de outros sujeitos e espaços em detrimento da instituição escolar financiada pelo poder público.

Após vinte anos da publicação da LDBEN, a educação em tempo integral, cada vez mais consta nos aportes legais e normativos, por exemplo, como no Plano de Metas Compromisso todos pela Educação, pelo Decreto 6.094, de 24 de dezembro de 2007, que em seu artigo $1^{\circ}$ diz que o Plano de Metas é a conjugação de esforços da União, Estados, Distrito Federal e Municípios no regime de colaboração das famílias e da Comunidade para melhorar a qualidade da Educação Básica, com foco na aprendizagem, para que possa diminuir o índice de analfabetismo e garantia do acesso a todos à Educação Básica. E apresenta, em uma de suas orientações, a ampliação da permanência dos estudantes na escola, ou sob sua responsabilidade, para além da jornada escolar, sendo que esse tempo integral pode se referir as atividades fora da escola (BRASIL, 2007a). Mas, que conhecimentos devem integrar essa jornada?

No que tange às áreas do conhecimento, Coelho (2009) contextualiza que a educação em tempo integral no Brasil remete à ampliação da jornada escolar dos estudantes, trazendo ou não novas disciplinas para o currículo escolar. A maioria das unidades de ensino que adota o modelo implementam a extensão do tempo em turno e contraturno escolar de forma que durante metade de um dia letivo os estudantes estudam as disciplinas de Português e Matemática, sendo as aulas extras, destinadas às áreas de Artes ou Esporte, entre outras.

Cavaliere (2009) acrescenta que educação de tempo integral se configura uma redundância, pois nas experiências e relações do cotidiano com a família, na rua, existe sempre uma constante aprendizagem. Mas, no que se refere ao contexto escolar, afirma que a escola de tempo integral pode proporcionar atividades diferentes do que se tem ensinado nas escolas de horário regular. Nesse sentido, precisa proporcionar atividades de esporte, lazer, estudos sociais, 
línguas estrangeiras, cuidados com a saúde, música, teatro, cultivo da terra, canto, ecologia, artesanato, corte e costura, informática, artes plásticas. Isso visando potencializar o desenvolvimento da dimensão cognitiva e ao mesmo tempo afetiva e relacional dos alunos, entre outras. Na perspectiva da autora, a escola de tempo integral seria um espaço que, além de propiciar o ensino de disciplinas curriculares, proporcionaria atividades potencialmente pedagógicas para expandir o conhecimento dos alunos.

No que diz respeito às expectativas em relação à ampliação da jornada escolar no Brasil, o Plano Nacional de Educação (PNE) (BRASIL, 2014) prevê até 2024, em sua meta 6, a educação em tempo integral em no mínimo $50 \%$ das escolas públicas, de forma a atender pelo menos $25 \%$ dos alunos da Educação Básica, focalizando, também, as comunidades mais pobres.

Pelo fato desse plano prever a reestruturação do padrão arquitetônico das escolas, s Mól (2015) entende que essa instituição ainda é importante para o desenvolvimento da educação em tempo integral. Mas, como também prevê a articulação da escola com outros espaços educativos, segundo a autora, a concepção apresentada no Plano remete ao modelo de organização da ampliação da jornada escolar "aluno em tempo integral", tal como descrito por Cavaliere (2009).

Percebemos que, conforme os aportes normativos, o investimento deve ser prioritário para comunidades pobres ou para crianças em situação de vulnerabilidade social, condizente com a concepção de proteção social, conforme Coelho (2009).

O estímulo a atividades desenvolvidas por entidades privadas de serviço social, tal como previsto no plano, conforme Mól (2015), segue uma tendência de responsabilização da sociedade pelas funções do estado. Para ela, essa estratégia não traz com clareza a necessidade de articulação das atividades ao projeto pedagógico das escolas, não permite vislumbrar uma educação integral em tempo integral, pois, corre -se o risco da realização de atividades fragmentadas e mescladas sem uma visão clara de educação integral, a partir de várias entidades da sociedade.

É preciso considerar que a educação em tempo integral trata da ampliação do tempo na escola, mas não necessariamente proporciona o desenvolvimento integral do sujeito. Em contrapartida, a educação integral considera o sujeito em sua condição multidimensional, não apenas na dimensão cognitiva, mas na compreensão do sujeito que é corpóreo, tem afetos e está inserido num contexto de relações, sendo o sujeito compreendido em sua dimensão 
biopsicossocial. Mas, entendemos que existe uma multiplicidade de sentidos que são atribuídos à educação integral, sendo assim, não existe consenso (CAVALIERE, 2009).

Segundo Cavaliere (2002), educação integral significa a formação global do indivíduo, que compreende os aspectos biológicos, psicológicos, sociais e cognitivos. Nessa concepção, a criança ou adolescente é um ser multidimensional. A relação social é a forma como as pessoas se interagem entre em si que é importante no desenvolvimento do educando para a melhoria da aprendizagem do aluno.

No Brasil, ao longo dos anos, tanto conservadores quanto os socialistas e liberais propuseram a educação integral, embora nem sempre defendendo as mesmas ideias e práticas, uma vez que a educação é caracterizada como um campo de disputas e suas propostas trazem a ideologia do grupo que a constituem (COELHO, 2010).

Sendo assim, concordamos com Coelho (2004), quando ela diz que é imperioso refletirmos sobre as concepções de educação integral existentes na história da educação, não com intenção de realizar transplantes de ideias, mas almejando elaborar uma concepção de educação integral que possa servir de fundamentos para atuais propostas de ampliação da jornada escolar diária.

Nesse sentido, a visão de Coelho (2009) vai ao encontro de Libâneo (2013), com foco no ensino-aprendizagem e a formação integral do indivíduo. Esse autor explica que a educação integral implica a formação da personalidade plenamente desenvolvida, multidimensional. Está ligada ao direito de cada ser humano desenvolver todas as suas dimensões físicas, intelectuais, afetivas, estéticas, independentemente das circunstâncias do seu nascimento, grupo social e cultura (LIBÂNEO, 2013).

$\mathrm{O}$ autor afirma que a educação integral compreende princípios, ações e procedimentos dentro de uma visão humanista e democrática que deveria ser característica de todas as escolas, compreende um amplo conjunto de práticas pedagógicas e ações socioeducativas voltadas para o desenvolvimento das potencialidades do ser humano.

Desse modo, Libâneo (2013) explica que a educação integral é a formação da personalidade plenamente desenvolvida, multidimensional e isso aparece desde a Antiguidade Clássica do mundo grego e romano. A educação integral está ligada ao direito de cada ser humano desenvolver todas as suas dimensões, quer sejam, físicas, intelectuais, afetivas, estéticas, 
independentemente das circunstâncias do seu nascimento, grupo social e cultura.

Mas na contemporaneidade, a educação integral e o tempo integral vêm apresentando novas caracterizações, seja pelas propostas do governo da ampliação da jornada diária escolar e sua adaptação ao tempo integral. Nesse sentido, quando refletimos sobre essa temática, consideramos que na atualidade a educação integral apresenta caracterizações que podem ser expressas pelas seguintes relações: educação integral na perspectiva de promover proteção integral a crianças e adolescentes; educação integral a partir da oferta de um currículo escolar integrado e; educação integral associada ao tempo integral, ou seja, a ampliação das horas diárias em que o aluno permanece na escola (COELHO, 2009).

Numa visão contemporânea, Moll (2010) considera a importância de uma maior integração entre os espaços formais de ensino e a sociedade, além de associar a educação integral à proteção das crianças e adolescentes em situação de vulnerabilidade. Entende que parcerias com a sociedade e a atuação de sujeitos voluntários amplia a formação dos alunos.

Nessa mesma perspectiva, Guará (2006), em uma visão de proteção social, fala da compreensão do homem como ser multidimensional, de forma que a educação integral deve englobar as atividades realizadas fora das escolas em quadras esportivas, laboratórios, espaços para atividades culturais que são atreladas em diversas dimensões (cognitiva, afetiva, ética, social, lúdica, estética, física, biológica). Neste sentido, a autora entende que a instituição escolar tem espaços sociais (institucionais ou não institucionais) que constrói comportamentos, juízos de valor, setores e formas de ser e estar no mundo. A partir desse entendimento que a centralidade da escola é reiterada, frente ao desafio de propor uma relação com as demais instituições da sociedade. Nesta perspectiva de análise, a educação integral supõe o desenvolvimento de todas as potencialidades humanas, com equilíbrio entre vários aspectos (GUARÁ, 2006).

Já Coelho (2009) defende a mesma perspectiva de Libâneo (2013), para o qual a educação integral deve desenvolver a formação integral do indivíduo de forma abrangente de suas dimensões física, social, entre outras. Por outro lado, Moll (2010) e Guará (2006) têm o mesmo ponto de vista em relação à educação integral, associando-a a proteção das crianças e adolescentes em situação de vulnerabilidade com o ensino-aprendizagem nas escolas ou em outros espaços.

Destacamos, em termos de política pública brasileira que se propôs a oferecer uma 
educação integral em tempo integral na primeira década do século XXI, o Programa Mais Educação, criado pela Portaria Interministerial n. 17, 24 de abril de 2007 (BRASIL, 2007c) e regulamentado pelo Decreto n. 7.083 de 2010 (BRASIL, 2010). Esse programa se constituiu como estratégia do Ministério da Educação para indução da construção da agenda de educação integral nas redes estaduais e municipais de ensino, prevendo uma educação em tempo integral com no mínimo sete horas diárias, por meio de atividades como: acompanhamento pedagógico, Educação Ambiental, Esporte e lazer, Direitos humanos em Educação, Cultura e Artes, Cultura Digital, Promoção da Saúde, Comunicação e uso de mídias, Investigação no campo das Ciências da Natureza e Educação Econômica (BRASIL, 2010).

A partir dessas reflexões sobre as concepções de educação integral, podemos dizer que o PME integra a visão contemporânea. O PME tinha como finalidade uma educação integral em tempo integral, mas tendo como prioridade apenas os alunos em situação de vulnerabilidade social e com baixo desempenho escolar. Defendeu a mobilização da sociedade para a melhoria da qualidade da educação (mas que qualidade?). Para tanto, indicava como protagonistas no oferecimento das atividades, voluntários da comunidade, associando educação integral com vivências em outros espaços, que não a escola, articuladas por outras entidades e sujeitos, sem ou com formação pedagógica, na contramão da concepção de educação integral defendida por Coelho (2009) e Libâneo (2010).

\section{CONCLUSÃO}

O estudo em questão permitiu a compreensão de que desde a LDBEN a progressiva ampliação da jornada escolar visando a escola de tempo integral foi prevista, mas que o quantitativo, em termos de carga horária, para a educação em tempo integral, só foi indicado no PNE de 2001. Esse plano, assim como o FUNDEB, o PNE de 2014 e o PME, definem educação em tempo integral a partir de 7 horas diárias de atividades escolares. No entanto, foi a partir do FUNDEB e do Plano de Metas Compromisso Todos pela Educação que as atividades para esse tempo integral também coincidiram com aquelas desenvolvidas sob a responsabilidade da escola, mas não necessariamente nela, o que é a âncora da concepção educativa do PME.

Essa extensão do espaço educativo também é aferida para a questão dos articuladores da educação em tempo integral, não restritos apenas aos profissionais da educação, podendo integrar 
outras entidades, públicas ou privadas, tal como previsto no PME e no PNE de 2014, embora o PNE de 2001 demarcasse a importância dos profissionais da educação.

Mas os sujeitos alvo dessa educação têm nome: aqueles em situação de vulnerabilidade, os quais devem ser enfocados, como coloca o PNE de 2001, o PME e o PNE de 2014. A preocupação com a questão do desempenho desses alunos é presente desde o PNE de 2001 e é reforçada no PME e no PNE de 2014, denotando uma educação eficienticista para o "alívio" dessa situação de vulnerabilidade, mas que responsabiliza os sujeitos pelo seu desempenho. Isso porque mascara que essa educação não é forjada para sua emancipação e que as razões de sua situação não se circunscrevem ao tempo de escola, tendo relação com a configuração da sociedade de classes.

No caso do PME essa educação ainda pretendia abarcar uma educação integral, a qual, na perspectiva já trabalhada nesse estudo, quer seja a do aluno em tempo integral, envolvia dimensões formativas oferecidas a partir da disponibilidade dos sujeitos da comunidade, das parcerias com a sociedade civil, além da proteção social.

Nesse sentido, foi possível perceber nos aportes normativos educacionais brasileiros, uma tendência a uma educação em tempo integral numa lógica de turno e contraturno que fragmenta o processo formativo, que tem vista proporcionar mais educação para os sujeitos pobres a partir de uma configuração pobre, envolvendo recursos humanos e materiais já disponíveis na sociedade, sejam eles com especificidade pedagógica ou não, com interesses que abarcam as necessidades das camadas mais pobres ou não.

Na contramão do discurso da melhoria da qualidade da educação, temos uma educação que parece (con)formar os sujeitos à caridade em uma sociedade posta como colaborativa, mascarando o fato dela ser cindida em classes e com interesse antagônicos, inclusive a respeito do que vem e deve contemplar mais educação.

\section{REFERÊNCIAS BIBLIOGRÁFICAS}

BRASIL. Lei n. 9.394 de 20 de dezembro de 1996.Estabelece as diretrizes e bases da Educação Nacional. Diário Oficial da União, Brasília, DF, 23 dez 1996. Disponível em: <http://www.planalto.gov.br/ccivil_03/LEIS/L9394.htm>. Acesso em 08 set. 2019.

BRASIL. Lei n. 10.172 de 09 de Janeiro de 2001.Aprova o Plano Nacional da Educação e dá outras providências. Diário Oficial da União, Brasília, DF,10 de jan.2001. Disponível em: <http://www.planalto.gov.br/ccivil_03/leis/leis_2001/110172.htm>. Acesso em 08 set. 2019.

BRASIL. Decreto n. 6.094 de 24 de abril de 2007. Dispõe sobre a implementação do plano de metas compromisso todos pela educação, pela União Federal, em regime de colaboração com municípios, distrito federal e estados, e a participação das famílias e da comunidade, mediante programas e ações de assistência técnica e financeira, visando a 
mobilização pela melhoria da qualidade da educação básica. Diário Oficial da União, Brasília, DF, 25 de abril de 2007a. Disponível em: < http://www.planalto.gov.br/ccivil_03/_ato2007-2010/2007/decreto/d6094.htm>. Acesso em 08 set. 2019.

BRASIL. Decreto n. 6.253, de 13 de novembro de 2007. Dispõe sobre o Fundeb, regulamenta a Lei n. 11.494, de 20 de junho de 2007. Diário Oficial da União, Brasília, DF,14 no 2007b. Disponível em: < http://www.planalto.gov.br/ccivil_03/_ato2007-2010/2007/Decreto/D6253.htm>. Acesso em 08 set. 2019.

BRASIL. Decreto n. 7083 de 27 de janeiro de 2010.Dispõe sobre o Programa Mais Educação-Diário Oficial da União, Brasília, DF, 27 jan. 2010. Disponível em: < http://www.planalto.gov.br/ccivil_03/_ato20072010/2010/decreto/d7083.htm>. Acesso em 08 set. 2019.

BRASIL. Lei n. 13.005 de 25 de junho de 2014: Aprova o Plano Nacional de Educação e dá outras providências.

Diário oficial da União, Brasília, DF, 25 jun. 2014. Disponível em:

<http://www.planalto.gov.br/ccivil_03/_ato2011-2014/2014/lei/113005.htm>. Acesso em 08 set. 2019.

BRASIL. Portaria Normativa Interministerial n. 17, de 24 de abril de 2007. Institui o

Programa Mais Educação que visa fomentar a educação integral de crianças, adolescentes e jovens, por meio do apoio a atividades socioeducativas no contra turno escolar. Diário Oficial da União, Brasília, DF, 26 de abril de 2007c. Disponível em: < http://portal.mec.gov.br/arquivos/pdf/mais_educacao.pdf>. Acesso em 08 set. 2019.

CAVALIERE, A.M. Quantidade e racionalidade do tempo de escola: debates no Brasil e no mundo. Teias, Rio de Janeiro, n.6, p.116-126, jul./dez.2002. Disponível em: < https://www.epublicacoes.uerj.br/index.php/revistateias/article/download/23934/16907>. Acesso em 08 set. 2019.

. Tempo de escola e qualidade na educação pública. Educação e Sociedade (impresso). Campinas, V.28, n.100-especial, 2007, p.1015-1035. Disponível em: <http://www.scielo.br/pdfles/v28n100/a1828100 2 . Acesso em 10 jul.2018.

. Escolas de tempo Integral versus alunos em tempo integral. In. Maurício, Lúcia Velloso. Em aberto 80. Educação Integral e tempo integral. Brasília, v.22, n80, p-51-65, abr. 2009. Disponível em: < http://congressoconhecer.com/inicio/arquivo/Texto_-_Ana_Maria_Cavaliere.pdf>. Acesso em 08 set. 2019.

COELHO, Lígia Martha C. da Costa. História(s) da Educação Integral. In: Maurício, Lúcia Velloso. Em aberto 80. Educação Integral e Tempo Integral. Brasília, v.22, n80, p-83-97, abr. 2009. Disponível em: < http://emaberto.inep.gov.br/index.php/emaberto/article/download/2222/2189>. Acesso em 08 set. 2019.

. Integração escola- território:' saúde 'ou ‘doença 'das instituições? In: Maurício, Lúcia Veloso(Org.). Tempos e espaços escolares: experiências, políticas e debates no Brasil e no Mundo. Rio de Janeiro, Ponteio: FAPERJ,2014. COELHO, Lígia Martha Coimbra da Costa. Plano Nacional de Educação 2014-2024-Meta 06:estratégias para qual tempo e para qual projeto de sociedade? Educação e Cultura Contemporânea (Online). v.33, p.102-120, 2016.Disponível em:http://periódicos.estacio.br/index.php/reeduc/article/viewArticle/2433.Acesso em:10 jul.2018.

GUARÁ, Isa Maria F. Rosa. É imprescindível educar integralmente. Caderno Cenpec: Educação, Cultura e Ação Comunitária

$n^{\circ}$. 2,2006

Disponível

em: http://cadernos.cenpec.org.br/cadernos/index.php/cadernos/article/download/168/197. Acesso em 08 set. 2019.

LIBÂNEO, José C. Didática na formação de professores :entre a exigência democrática de formação cultural e científica e as demandas das práticas socioculturais. In: Santos, Aiko; Suando, João H.; Suando, Marilda V.R.(Org.). Didática e formação de professores: complexidade e transdisciplinaridade. Porto Alegre: Salina,2013.

LIBÂNEO, J. C. Escola de Tempo Integral em Questão: lugar de acolhimento Social ou de ensino-aprendizagem? In: BARRA, V. M. L. (Org.) Educação: ensino, espaço e tempo na escola de tempo integral. Goiânia: UFG, 2015, p.257-308.

MÓL, Saraa César. Programa Mais Educação: mais de qual educação? 185 fl. 2015. Dissertação (Mestrado em Processos Socioeducaivos e Práticas Escolares) - Programa de Pós-Graduação em Educação da Universidade Federal de São João del-Rei, São João del-Rei.

MOLL, Jaqueline. Escola de Tempo Integral. In. Oliveira, Dalila Andrade et. al. Dicionário trabalho, profissão e condição docente. Belo Horizonte: UFMG/Faculdade de Educação, 2010.

MOLL, J. A agenda da educação integral: compromissos para sua consolidação como política pública. In: Moll, Jaqueline .et al. Caminhos da Educação Integral no Brasil: direitos a outros tempos e espaços educativos. Porto Alegre: Penso, 2012, p.129-143. 